\title{
Observations of turbulence beneath sea ice in southern McMurdo Sound, Antarctica
}

\author{
C. L. Stevens ${ }^{1}$, N. J. Robinson ${ }^{1,2}$, M. J. M. Williams ${ }^{1}$, and T. G. Haskell ${ }^{3}$ \\ ${ }^{1}$ National Institute for Water and Atmospheric Research (NIWA), Greta Point Wellington, New Zealand \\ ${ }^{2}$ University of Otago, Dunedin, New Zealand \\ ${ }^{3}$ Industrial Research Ltd (IRL), Gracefield, Lower Hutt, New Zealand
}

Received: 10 June 2009 - Published in Ocean Sci. Discuss.: 7 July 2009

Revised: 24 September 2009 - Accepted: 27 September 2009 - Published: 26 October 2009

\begin{abstract}
The first turbulence profiler observations beneath land fast sea ice which is directly adjacent to an Antarctic ice shelf are described. The stratification in the $325 \mathrm{~m}$ deep water column consisted of a layer of supercooled water in the upper $40 \mathrm{~m}$ lying above a quasi-linearly stratified water column with a sharp step in density at mid-depth. Turbulent energy dissipation rates were on average $3 \times 10^{-8} \mathrm{~m}^{2} \mathrm{~s}^{-3}$ with peak bin-averaged values reaching $4 \times 10^{-7} \mathrm{~m}^{2} \mathrm{~s}^{-3}$. The local dissipation rate per unit area was estimated to be $10 \mathrm{~m} \mathrm{Wm}^{-2}$ on average with a peak of $50 \mathrm{~m} \mathrm{Wm}^{-2}$. These values are consistent with a moderate baroclinic response to the tides. The small-scale turbulent energetics lie on the boundary between isotropy and buoyancy-affected. This will likely influence the formation and aggregation of frazil ice crystals within the supercooled layer. The data suggest that the large crystals observed in McMurdo Sound will transition from initial growth at scales smaller than the Kolmogorov lengthscale to sizes substantially (1-2 orders of magnitude) greater than the Kolmogorov scale. An estimate of the experimentaveraged vertical diffusivity of mass $K_{\rho}$ yields a coefficient of around $2 \times 10^{-4} \mathrm{~m}^{2} \mathrm{~s}^{-1}$ although this increased by a factor of 2 near the surface. Combining this estimate of $K_{\rho}$ with available observations of average and maximum currents suggests the layer of supercooled water can persist for a distance of $\sim 250 \mathrm{~km}$ from the front of the McMurdo Ice Shelf.
\end{abstract}

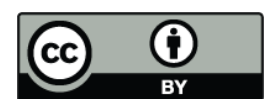

Correspondence to: C. L. Stevens (c.stevens@niwa.cri.nz)

\section{Introduction}

Ice shelf cavities contain large reservoirs of seawater below the surface freezing point, giving rise to some unique thermohaline properties (Jacobs et al., 1996; Williams et al., 2001). Rising plumes containing buoyant glacial meltwater are constrained by the ice shelf basal plane, but upon exiting the cavity can be significantly supercooled and laden with ice crystals (e.g. Payne et al., 2007; Holland et al., 2007). The fate and transformation of these waters influences the development of regional sea ice which in turn has a significant impact on climate (Hellmer, 2004). This relationship, combined with greater than predicted losses in Arctic sea ice in recent years (Stroeve et al., 2007), suggests there is some urgency in understanding the processes controlling transport and mixing in high southern latitudes and their influence on the sea ice-ocean system.

McMurdo Sound's relative accessibility makes it a useful natural laboratory for examining such processes. However, more than this, it's proximity to the McMurdo and Ross Ice Shelves (Fig. 1) means it has intrinsic importance as a conduit for shelf-affected seawater. Recent analyses have quantified the large scale flows and internal wave processes in McMurdo Sound region (Albrecht et al., 2006; Robinson et al., 2009). At smaller scales, Jacobs et al. (1981) examined glacier tongue-affected water $15 \mathrm{~km}$ to the north of the present site and resolved diffusive-convective layering over horizontal scales of $5 \mathrm{~km}$ or more. Some of the first under-ice turbulence observations were recorded in McMurdo Sound but from very inshore locations (Mitchell and Bye, 1985). Very recently Muench et al. (2009) quantified turbulence on the shelf slope $800 \mathrm{~km}$ to the north. To date there has been little oceanographic work focusing on turbulence and mixing

Published by Copernicus Publications on behalf of the European Geosciences Union. 

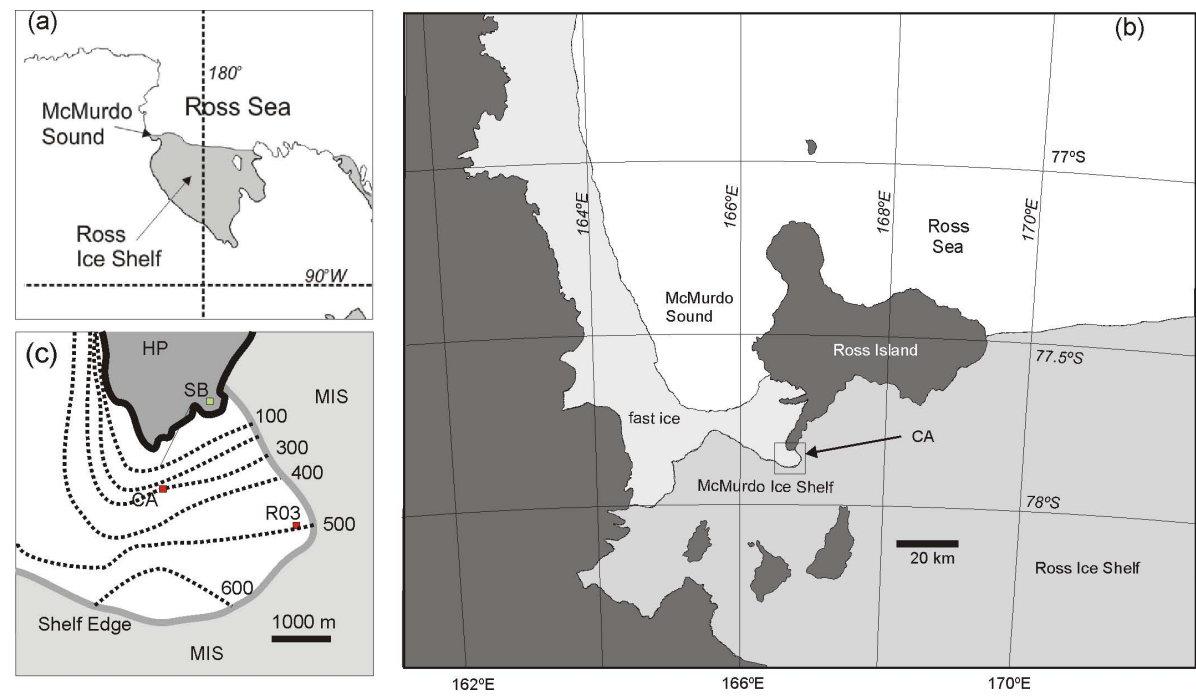

Fig. 1. Map showing (a) the McMurdo Sound field site in the context of the Ross Sea and the Ross Ice Shelf, (b) Ross Island and environs including the Ross Ice Shelf, McMurdo Ice Shelf, Ross Sea and McMurdo Sound - the detailed sampling location is marked CA and expanded in (c). This shows the sampling location (CA), locations of Robinson et al. (2009) data (R03) and Scott Base (SB).

in the fast ice-shelf interface region. As well as directly influencing biological production (Arrigo et al., 2008), these small-scale processes influence ice formation and growth under sea ice and ice shelves (McPhee and Morison, 2001; Leonard et al., 2006; Stevens et al., 2006; McPhee, 2008; McGuiness et al., 2009). One important pathway for this influence is the effect on appearance and growth of frazil ice crystals both in their role as the initial building block of sea ice and as further contributors once ice thickens (Leonard et al., 2006). The objectives of the present work are to (i) document the observed turbulent properties in this under-sampled location, (ii) quantify the likely influence of this turbulence on the transport of ice shelf-influenced water and frazil ice crystals and (iii) compare the relative influences of the ice cover and the local topography on the turbulence.

\section{Scales of turbulence}

Turbulent mixing is characterized using the rate of dissipation of turbulent energy $\left(\varepsilon, \mathrm{m}^{2} \mathrm{~s}^{-3}\right)$. This dissipation rate is part of a balance whereby the generation of turbulent kinetic energy is partitioned into changes in velocity structure, potential energy and dissipation of turbulent kinetic energy (Tennekes and Lumley, 1972). Viewed from the perspective of length scale, instability of some form initiates an energy cascade that creates eddies at an "energy-bearing" vertical scale, $L_{e}$. There are both upper and lower limits on the length scales in this cascade. At the largest scale, the earth's rotation limits growth of the boundary-layer to a scale related to a planetary lengthscale $\sim 0.03 u_{*} / f$ where $u_{*}$ is the friction velocity and $f$ is the Coriolis parameter (McPhee, 2008). However, close to topography there is the potential that local boundary effects dominate over this streering. Water column stratification provides an upper limit on eddy size so that as the energy bearing scale is created it is limited in initial scale by buoyancy. This limit is given by the Ozmidov length scale

$L_{O z}=\left(\frac{\varepsilon}{N^{3}}\right)^{1 / 2}$

where $N$ is the buoyancy frequency (the square of which is given by $N^{2}=\left(g / \rho_{0}\right) \partial \rho / \partial z$; gravitational acceleration $g$, reference density $\rho_{0}$, and $\partial \rho / \partial z$ is the vertical derivative of density). The energy is transformed from this large scale to smaller and smaller scales until it reaches a scale at which its variability is dissipated by viscosity. The Kolmogorov scales define these smallest scales of turbulent variability and provide the lower limiting length scale

$L_{K}=\left(\frac{v^{3}}{\varepsilon}\right)^{1 / 4}$

where $v$ is the kinematic viscosity.

Non-dimensional parameters based on the scales $L_{K}, L_{e}$, and $L_{O z}$ enable the categorisation of instantaneous samples to be placed in a mechanical context by effectively locating the observed turbulence between these scales in a mechanistic framework. The turbulent Froude number is described as the ratio (to the power 2/3) of the stratification limit to energy-bearing scale (Stacey et al., 1999; Imberger and Ivey, 1991);

$F r_{t}=\left(\frac{L_{O z}}{L_{e}}\right)^{2 / 3}$.

If buoyancy-limited eddies are smaller than the energybearing scale $\left(F r_{t}<1\right)$ then eddies are squashed to the point 
that growth is transformed into internal waves. Similarly, the turbulent Reynolds number

$R e_{t}=\left(\frac{L_{e}}{L_{K}}\right)^{4 / 3}$

compares the energy-bearing scale with the minimum turbulent length scale. This parameter effectively quantifies the scales turbulence must traverse in the cascade between generation and dissipation. A similar analysis for scalar properties, for example the dissipation rate of thermal variance, can be developed (Tennekes and Lumley, 1972) but temperature variance is not readily resolvable in the present quasiisothermal conditions (see Sect. 2.3).

The length scales $L_{K}, L_{e}$, and $L_{O z}$ can be resolved using either profiles through the water column (e.g. Robertson et al., 1995; Fer and Widell, 2007; Rainville and Winsor, 2008) or, as has been more typical in sub-sea ice turbulence studies, through the use of timeseries of velocity fluctuations at fixed depths (Mitchell and Bye, 1985; McPhee, 1992, 2004). A number of studies have sought to place turbulence observations in the $F r_{t}-R e_{t}$ domain (Imberger and Ivey, 1991; Stacey et al., 1999; Keeler et al., 2005) but none so far in a polar context.

Here we relate the turbulence scaling to sea ice processes associated with supercooled sea water. Significant volumes of supercooled water are typically observed in the outflow regions of ice shelves. Water formed through ice-ocean interaction at depth becomes supercooled as it rises through the water column on emergence from the sub-ice shelf cavity. Transport and dilution of this water along the underside of sea ice cover represents a significant ocean heat sink, and hence is a factor in the growth of land fast sea ice adjacent to ice shelves (Leonard et al., 2006). Furthermore, if this supercooled water encounters sufficient nucleation opportunities, suspended frazil ice forms within the water column (Leonard et al., 2006). Turbulence will then influence the growth and aggregation of these suspended ice crystals (McGuiness et al., 2009) which can become integrated into the sea ice (Leonard et al., 2006). In the following we present a description of the observational techniques and analysis methodology and then the essential results. The Discussion then considers the questions posed above, both in the light of the data presented here, and in the context of studies in related systems.

\section{Location and methods}

\subsection{Southern McMurdo Sound}

Observations of oceanic turbulence were recorded beneath a sea ice camp located on the fast ice in the newly-gazetted Haskell Strait, southern McMurdo Sound (77 52.257' S; 166 $\left.44.041^{\prime} \mathrm{E}\right)$. The primary measurements were resolved using

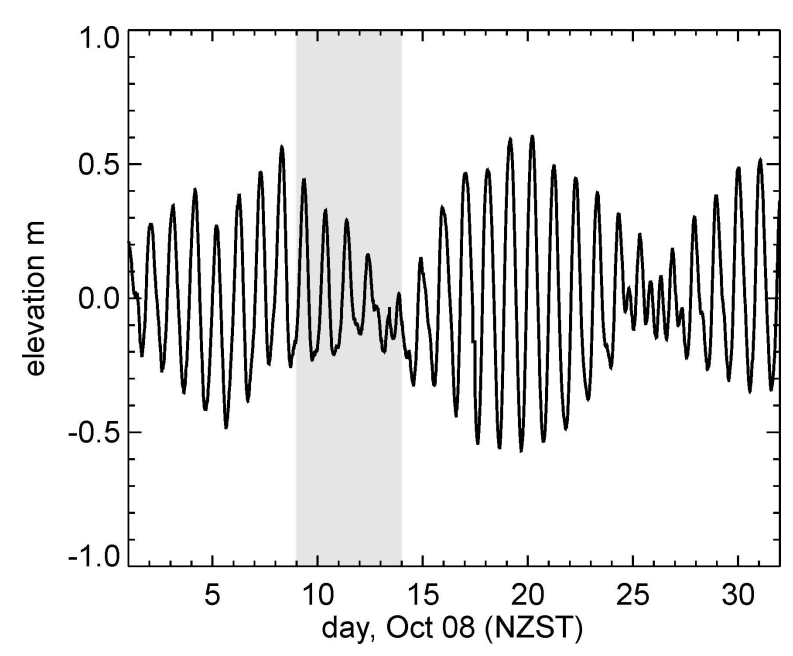

Fig. 2. Measured tidal elevation from Scott Base, the present sampling extended over the shaded period.

a shear profiler through a hole in the $\sim 2 \mathrm{~m}$ thick fast multiyear ice in $325 \mathrm{~m}$ of water around $2 \mathrm{~km}$ from the southern tip of Hut Point Peninsula (Fig. 1). The field site was more than $50 \mathrm{~km}$ from extensive open water and so was not directly influenced by wind, nor were there any nearby grounded icebergs acting as large sources of atypical local turbulence. The mainly diurnal spring tidal elevation amplitudes are of the order of $1.2 \mathrm{~m}$ (Goring and Pyne, 2003) and our measurements commenced just after spring tide and extended through to neap tide (Fig. 2). Robinson et al. (2009) measured flows in the region ( $7752.77^{\prime} \mathrm{S} ; 16650.04^{\prime} \mathrm{E}, 2.6 \mathrm{~km}$ to East, Fig. 1c) that, when vertically-averaged, peaked at around $0.25 \mathrm{~m} \mathrm{~s}^{-1}$. However, they also observed that maximum flows occurred during the neap of the tidal cycle, an explanation for which might be that, with weaker vertical mixing comes stronger buoyancy-driven flows (Stacey et al., 2001).

\subsection{Microstructure profiling}

Shear profiles were resolved with a Rockland VMP500 microstructure loose-tethered free-fall profiler with dual shear sensors (Macoun and Lueck, 2004; Lueck, 2005). The profiler did not fall all the way to the bed because of cable length restrictions, and so stopped as much as $50 \mathrm{~m}$ above the bed, depending on flow conditions. Hence, the benthic boundarylayer was not resolved in these data. The profiler was typically removed from the water in between profiles to avoid platelet growth (a common issue in the McMurdo region, see Leonard et al., 2006) as well as minimizing interference with and by seals that would use the hole every 40 or so minutes. This removal then required the profiler be left in the hole for several minutes prior to each profile to thermally equilibrate (Morison et al., 1994).

Energy dissipation rates were resolved from the dual shear probe profiler using standard techniques (Prandke, 2005). 


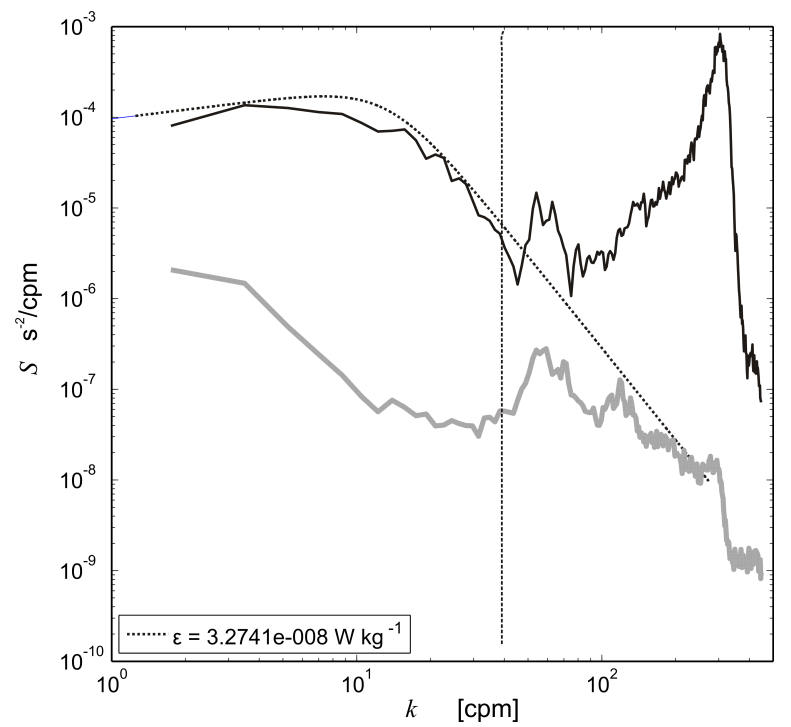

Fig. 3. Example shear spectrum including accelerometer spectrum (grey) and model dissipation spectrum (dotted; dissipation rate shown). The vertical dashed line is the cutoff where the vibration started to influence the spectrum.

Analysis first corrected for profiler vibration, identified the reliable section of the spectrum by comparing with the vibration spectrum derived from accelerometers, and then isolated a dissipation spectrum (Fig. 3). The tail beyond the noise limit was substituted with the tail of the Nasmyth model spectrum. The dissipation rate was then calculated with the integral $\varepsilon=7.5 v \int S d k$ (e.g. Roget et al., 2006; Prandke, 2005) where $k$ is the wave number and $S$ is the shear spectrum. The noise floor in terms of $\varepsilon$ was around $3 \times 10^{-10} \mathrm{~m}^{2} \mathrm{~s}^{-3}$. This was, however, not a fixed quantity as it depended on a number of variables like cable influence that were not exactly the same in every profile. Forty six profiles were recorded with a total profiled distance of $11 \mathrm{~km}$. The data were separated into $5 \mathrm{~m}$ bins that were overlapped by $50 \%$ and so provided 4370 estimates of dissipation above the noise floor.

The highly variable density structure makes it difficult to properly determine the vertical structure of temporallyaveraged profiled properties. We referenced individual profiles to a new depth coordinate by cross-referencing with a time-averaged density profile. This density profile was an average derived from data recorded using Seabird (SBE) conductivity and temperature sensors mounted on the profiler which enabled calculation of temperature and salinity. At the temperatures encountered in the region (i.e. $-1.91 \pm 0.03^{\circ} \mathrm{C}$ ), the density field was almost totally dominated by salinity. Temperature, therefore, plays a role only (i) as a nearly passive tracer and (ii) as an indicator of the presence of supercooled fluid. The buoyancy frequency $N$ was calculated using the sorted, equilibrium density profile.

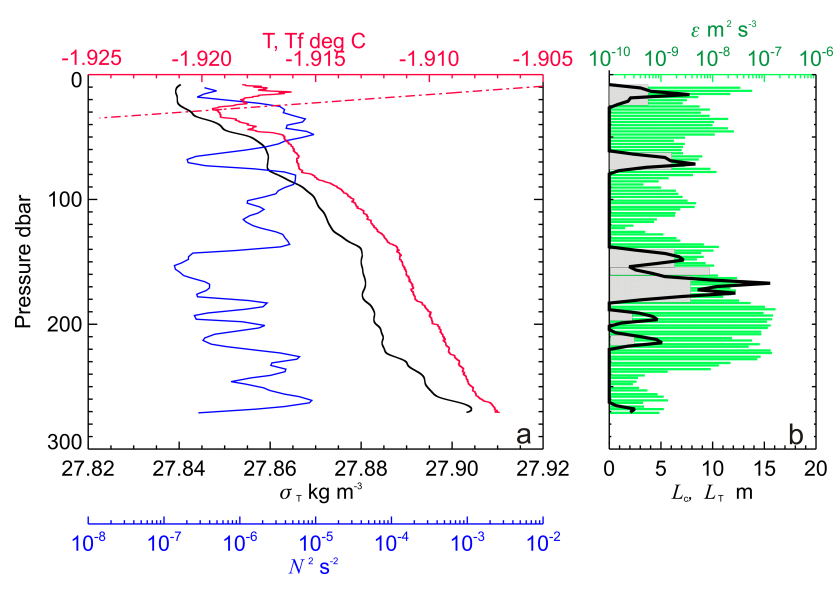

Fig. 4. Example of a single profile showing (left) sorted density $\sigma_{T}$ (black), buoyancy frequency squared (blue), and temperature (red) and the in situ freezing temperature of water (red dash-dot). The right panel shows the centred lengthscale $L_{c}$ (black) overlying the Thorpe scale segments (rectangular boxes). The dissipation rate $\varepsilon$ estimates are shown as green bars.

The temperature and salinity profiles also made it possible to derive a vertical displacement scale that is a proxy for $L_{e}$ (Dillon, 1982). Here we use the centred lengthscale, $L_{c}$, by associating eddy scales with their centre rather than their edge (Imberger and Boashash, 1986). $L_{c}$ is essentially a version of the Thorpe scale. Here it is derived by (i) first applying a low pass filter/threshold on the density profile to account for sensor spatial resolution (Galbraith and Kelley, 1996), (ii) sorting to obtain a monotonic density profile, (iii) placing the scale at the mid-point of the resorting lengthscale, and finally (iv) bin-averaging the results. The sensor limitations mean that there will be far fewer reliable estimates of $L_{c}$ than of $\varepsilon$. This processing (see example in Fig. 4) provided all the elements required for the lengthscale and phasespace analysis; i.e., $L_{e}, L_{O z}, L_{K}, F r_{t}$ and $R e_{t}$. It is possible to mount fast fp07 thermistors on the VMP500 in order to directly estimate $\chi_{\theta}$, the rate of dissipation of thermal variance which is the thermal equivalent to $\varepsilon$. However, our experience with using fp07s mounted on SCAMP thermal gradient profilers in these quasi-isothermal conditions suggests it is very difficult to resolve thermal gradient spectra above the noise floor even with the SCAMP's direct analogue derivative. Furthermore, the thermistors are expensive but less robust than a shear sensor and are quickly damaged by the presence of frazil crystals in the water column. Consequently, it was not possible to directly measure $\chi_{\theta}$. Instead vertical diffusivity of mass $K_{\rho}$ was resolved through use of two bulk approaches. The commonly-used Osborn (1980) model

$$
K_{\rho O}=\Gamma \frac{\langle\varepsilon\rangle}{\left\langle N^{2}\right\rangle}
$$

typically assumes $\Gamma=0.2$ and the ensemble averages \langle\rangle were found from the depth-corrected bin-average. $\Gamma$ is not a 


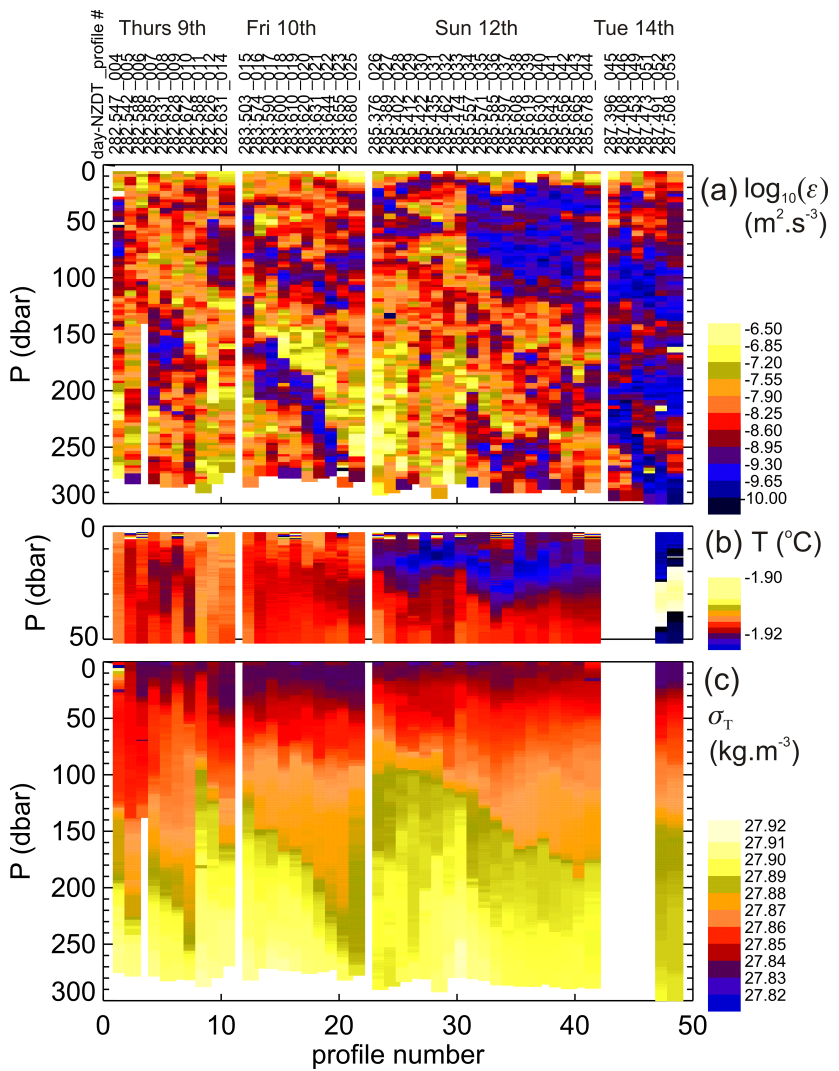

Fig. 5. Overview results from VMP showing (top) shear, (middle) upper water column temperature and (bottom) density in the form of $\sigma_{T}$. The four data days are separated by a blank profile column and bad profiles have been discarded so "profile number" is arbitrary and the actual profile number is in the text on the top of the plot along with local time (NZDT).

universal constant however and should be considered as an upper bound (e.g. Fer and Widell, 2007). Shih et al. (2005) use numerical simulations to propose an alternative diffusivity formulation for the case where $\varepsilon /\left(v N^{2}\right)>100$, denoted here as

$K_{\rho S}=2 v\left(\frac{\langle\varepsilon\rangle}{v\left\langle N^{2}\right\rangle}\right)^{1 / 2}$

In the following we calculate and compare both.

\section{Results}

The majority of the sampling period captured phases where the isopycnals at the sampling location were moving deeper into the water column with time (Fig. 5). The downward propagation speed of the isopycnals was around $3.5 \mathrm{~mm} \mathrm{~s}^{-1}$. In addition there were sharp rises in density structure reminiscent of internal bores. This is most apparent in profile 8 , and to a lesser extent profile 21 , where in the time between profiles the isopycnals rose by $50-100 \mathrm{~m}$. The "fronts"

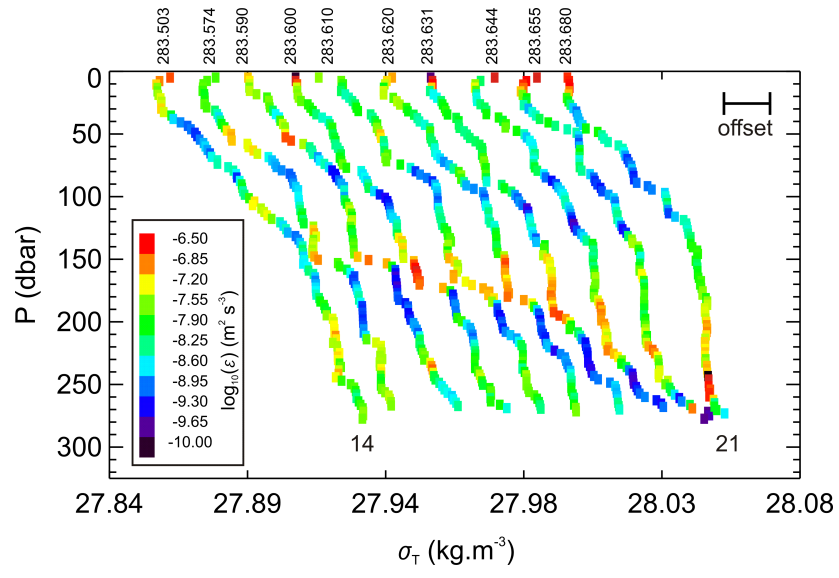

Fig. 6. Waterfall plot showing offset density profiles (starting with zero offset in the left-most profile) from Friday the 10 October, 2008 where each profile is colour coded with dissipation rate.

of the apparent bores were variable in their dissipation rate signature in that the front around profile 8 had only a weak increase in $\varepsilon$ whereas the front around profile 21 sustained some of the highest $\varepsilon$ of the observation period. This is best illustrated with dissipation rate-coded offset density profiles (Fig. 6) which show bands of high and low dissipation rate that tended to follow the downward pattern. The local $\varepsilon$ peaks were clearly located at the top of the main deepening pycnocline although by profile 21 the high dissipation region covers over $70 \mathrm{~m}$. Potentially these high dissipation events relates to instability in the high shear as some form of bore or flow-topography interaction develops. There is a shallower pycnocline at around $80-100 \mathrm{~m}$ but this does not move as much vertically nor does it sustain such high $\varepsilon$.

There was also a generally elevated dissipation rate in the uppermost measurements $8-13 \mathrm{~m}$ beneath the ice with a clear increasing trend in $\varepsilon$ moving closer to the ice from a depth of about $30 \mathrm{~m}$. Consideration of the temperature data expanded in the middle panel of Fig. 5 shows distinct differences between the first two days and the second two days, with colder water appearing around the start of sampling on day 3 (profile 23). The colder water was actually centred between 15 and $30 \mathrm{~m}$ depth. Note that the weak influence of this temperature effect was dominated by salinity and the water was lighter. There is a hint that this effect increased on day 4.

There was a strong change in water column characteristics at profile 31 where there seemed to be a strong jump in density at around 150-200 m, while the rest of the density structure remained largely unchanged. Directly after this time the water column variability seemed to rapidly dampen, with the dissipation rate decreasing by an order of magnitude. The only other systematic difference in dissipation rate occurred during the last sampling day when measured dissipation rates were universally lower throughout time and depth. Unfortunately, due most likely to frazil ice fouling, the scalar 
Table 1. Turbulence parameter statistics ( ${ }^{\mathrm{a}}$ the upper limit imposed by the dissipation measurement noise floor).

\begin{tabular}{|c|c|c|c|}
\hline & Mean & $\begin{array}{l}\text { Standard } \\
\text { deviation }\end{array}$ & $\begin{array}{r}\text { Maximum } \\
\text { (bin mean) }\end{array}$ \\
\hline $\begin{array}{l}\text { Dissipation rate } \\
\varepsilon\left(\mathrm{m}^{2} \mathrm{~s}^{-3}\right)\end{array}$ & $3.0 \times 10^{-8}$ & $9.0 \times 10^{-8}$ & $2.0 \times 10^{-7}$ \\
\hline $\begin{array}{l}\text { Vertical diffusivity } \\
\text { of mass } K_{\rho S}\left(\mathrm{~m}^{2} \mathrm{~s}^{-1}\right)\end{array}$ & $2.0 \times 10^{-4}$ & $5.0 \times 10^{-4}$ & $1.0 \times 10^{-2}$ \\
\hline$L_{K}(\mathrm{~m})$ & 0.003 & 0.001 & $0.008^{\mathrm{a}}$ \\
\hline$L_{c}(\mathrm{~m})$ & 8. & 9. & 60 \\
\hline$L_{O z}(\mathrm{~m})$ & 6.3 & 13. & 700 . \\
\hline
\end{tabular}

sensors were only working for a few casts on the last day. However, these casts showed that the lower part of the water column had relatively low density and that there was less cast to cast variability. This last sampling day was also when the tidal amplitude range was smallest (Fig. 2). Robinson et al.'s (2009) velocity data, from nearby but a different season (summer) and year (2003), show that vertically-averaged currents were not necessarily smaller on neap tide. However, in the present microstructure data it appears that the dissipation rates were substantially smaller during neap tide.

There were only subtle differences in the vertical distribution of properties in the bin-averaged profiles (Fig. 7) but at the broadest level the stratification was separated almost at mid-depth into lower and upper regions with the upper part of the water column sustaining $N^{2} \approx 3 \times 10^{-6}$ $(\mathrm{rad} \mathrm{sec})^{-2}$ whereas the lower portion was around half of this (Fig. 7a). The experiment-average energy dissipation rate $\varepsilon$ (Fig. 7b) was $3 \times 10^{-8} \mathrm{~m}^{2} \mathrm{~s}^{-3}$ with peak values reaching $4 \times 10^{-7} \mathrm{~m}^{2} \mathrm{~s}^{-3}$. The same partitioning was seen with the lower water column being around a factor of 3 more dissipative than the upper water column.

The under ice boundary layer was also apparent in the uppermost $35 \mathrm{~m}$ of the time-averaged profiles where the averaged dissipation rate rose with proximity to the underside of the ice (Fig. 7b). Energy dissipation rates were elevated in the shallowest reliable data bin (starting at $8 \mathrm{~m}$ depth $6 \mathrm{~m}$ beneath the underside of the ice) reaching a maximum of $2 \times 10^{-7} \mathrm{~m}^{2} \mathrm{~s}^{-3}$. This layer of elevated dissipation rate decreased from this level over the subsequent $15 \mathrm{~m}(8-28 \mathrm{~m}$ depth, Fig. 7b).

There were several isolated events generating high dissipation rates in a single isolated bin for a single profile. These were typically at mid-depth (Fig. 7b) and located in the centre of the density structure where the large scale velocity shear is typically concentrated and where there is likely the greatest variability. Essentially, we sampled sufficiently of- ten to capture one or two of the rare but highly energetic events. There was no increase in $\varepsilon$ at the base of the profiles so it was likely that profiler did not penetrate the bottom boundary layer.

The relatively small variability in $N^{2}$ meant that the two estimates of $K_{\rho}$ mirrored the $\varepsilon$ record quite closely (Fig. 7c). The Shih et al. (2005) estimate is around a factor of 15 smaller than the Osborn estimate (Fig. 8) and following Fer and Widell (2007) will be used here except where noted. Additionally, it is instructive to note that there was an almost order of magnitude difference in $K_{\rho S}$ introduced by considering instantaneous values of $\varepsilon$ and $N^{2}$, rather than ensemble averages. The increase largely comes about because of the locally small $N^{2}$ generated by energetic events. The estimated vertical diffusivity of mass $K_{\rho S}$ had an average value of $10^{-4} \mathrm{~m}^{2} \mathrm{~s}^{-1}$ (Fig. 7c) with values near the ice rising to almost $10^{-3} \mathrm{~m}^{2} \mathrm{~s}^{-1}$.

Turbulence properties and scales are collated in Table 1. Kolmogorov lengthscales $L_{K}$ were in the range $1-8 \mathrm{~mm}$, with a small proportion of sample bins containing values that fell on the noise floor. In these cases, at lower dissipation rates one would expect the $L_{K}$ to be larger than $8 \mathrm{~mm}$. With respect to those scales that were measurable, the most common $L_{K}$ was around $2 \mathrm{~mm}$. Contrary to this narrow range, both $L_{O z}$ and $L_{c}$ extended over three decades from $0.1 \mathrm{~m}$ in size and up - with some values reaching $50 \mathrm{~m}$ or more. The bias was substantially towards the condition $L_{c}<L_{O z}$, the implications of which will be considered in the next section.

\section{Discussion}

\subsection{Turbulence quantities}

Here we compare the observations with both profiler (Fer and Widell, 2007; Robertson et al., 1995; Rainville and Winsor, 2008) and timeseries (Fer and Widell, 2007) observations made beneath sea ice. As topography in the form of the $3 \mathrm{~km}$ wide Hut Point Peninsular $1 \mathrm{~km}$ to the north of the sampling appears to play a large role it is also worthwhile comparing results with examples of shelf break (St. Laurent, 2008) and strait flows (Wesson and Gregg, 1995).

Robertson et al. (1995) recorded microstructure in the Weddell Sea at an ice camp well offshore beneath multiyear ice. Their focus was mainly on mixing in the deep pycnocline. However, their observations also showed dissipation rates of around $10^{-8} \mathrm{~m}^{2} \mathrm{~s}^{-3}$ in the upper ocean and their general flow speeds were in the range of $0.10-0.25 \mathrm{~m} \mathrm{~s}^{-1}$. This near-surface dissipation rate is around a factor of 4 less than that observed here despite the background flows being similar. The structure here sustained comparable, if slightly lower, $\varepsilon$ to that observed by Fer and Widell (2007) in an Arctic fiord, again with similar flow speeds.

There are few direct comparisons, polar or otherwise, between profile and timeseries observations of turbulence. In a 

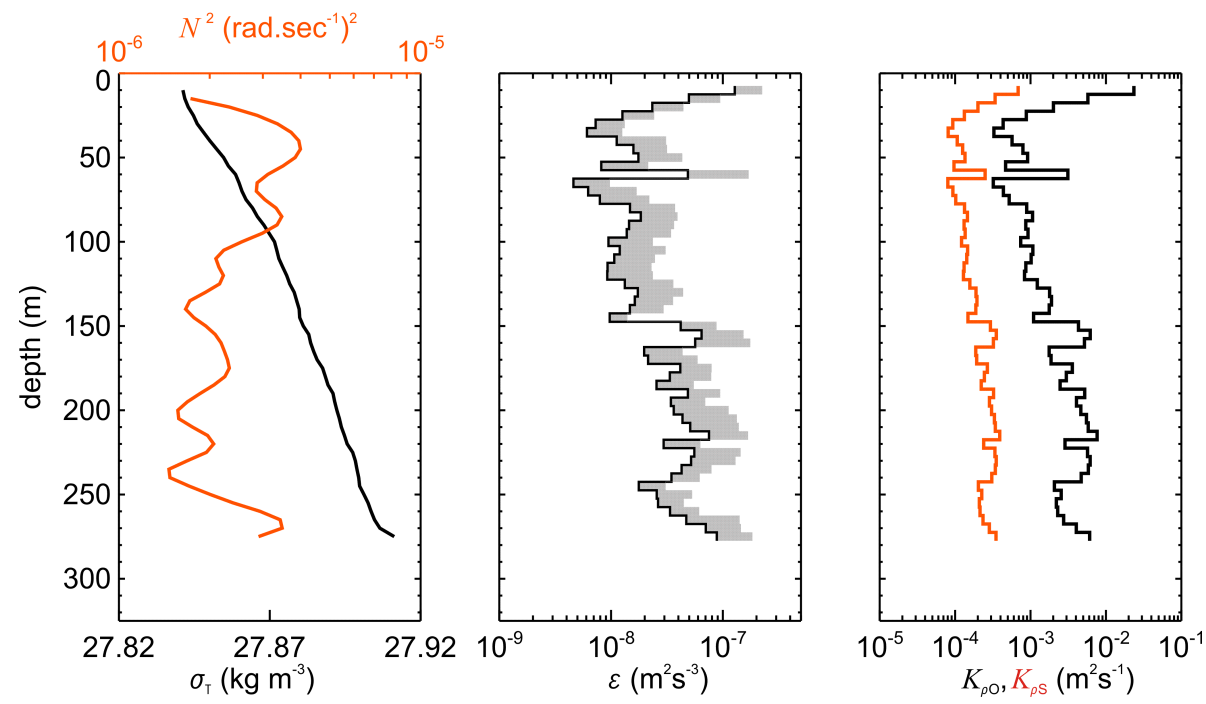

Fig. 7. Profiles of (a) average density anomaly and (orange) associated buoyancy frequency, (b) energy dissipation rate $\varepsilon$ (dark line shows bin-averages, shaded region shows bin-average plus standard deviation), and (c) vertical diffusivity estimates where Osborn $K_{\rho} O$ (black) and Shih et al. (2005) $K_{\rho S}$, (red) are based on ensemble-averages.

polar context Fer and Widell (2007) found quite good comparison between the two methods and that, in some instances, the profiled dissipation rates even exceeded the timeseries rates. McPhee and Stanton (1996) made direct comparisons of stationary and profiling microstructure measurements at the edges of freezing leads, and at depths within range of the measurements described here. They were able to estimate heat flux from thermal variance measurements and observed reasonably good agreement for eddy diffusivities. The good agreement suggests there is a lower degree of variability at longer periods (i.e. profile interval timescales) than in open water surface layers. It is usual that timeseries observations generate higher estimates of dissipation rate than profiled observations with the argument being that the poorer temporal resolution in the profiled data means that the trade-off in seeking vertical structure reduces the ability to capture temporal variability (Stevens and Smith, 2004).

Integrating the average dissipation rate for the present McMurdo data, $\int_{H}^{0} \rho \varepsilon d z$, suggests dissipation to be $10 \mathrm{~m} \mathrm{Wm}^{-2}$ although the maximum vertical average of $\varepsilon$ suggests a maximum dissipation during these tides of around 50 times greater but perhaps for an hour or less. This estimate of vertically-integrated $\varepsilon$ is likely a lower bound as we did not sample during the larger spring tides, nor did we sample the benthic boundary layer. During these phases we expect maximum speeds to be twice those observed here (as suggested by Robinson et al., 2009). As $\varepsilon$ is proportional to speed-cubed we would expect maximum dissipation rates to be almost a factor of 10 larger.

When comparing the present results with microstructure experiments in non-ice covered, but otherwise similar, situa- tions (i.e., large strait flows), this level of dissipation rate is, as one would expect, low compared to high energy locations like the crest of the Gibraltar sill (Wesson and Gregg, 1994) where average values were around two orders of magnitude greater than here. The present results are more in line with observations by St. Laurent (2008) in the South China Sea.

It is important to recognise that this level of tidal dissipation rate is not an open ocean value and that the present situation has two constraining features: (i) the presence of both an ice shelf and sea ice, and (ii) the tide-topography interaction. Sea ice will serve to remove the influence of wind but add the effect of drag on the under-side of the ice. The present observations suggest also that locally dissipation appears to be "small" in terms of that used by large scale modelling (e.g. Zaron and Egbert, 2006). Furthermore, with regard to direct measurements, by not profiling the bottom $10-20 \%$ of the water column, it is possible that we underestimate the total dissipation (St. Laurent, 2008).

In an instantaneous sense the rate of dissipation of energy is only weakly related to the energy bearing scale as there is typically a lag between production and dissipation to the extent that related quantities are not captured in the same profile. There is a stronger link between the observed energy bearing scale and the stratified limit to scale quantified by the $L_{O Z}$ scaling (Fig. 9). The self-consistency between finescale scalar-derived $\left(L_{c}\right)$ and microscale-derived (the $\varepsilon$ in $L_{O z}$ ) values is strong support for confidence in the data.

Consideration of the locus of the results in the turbulent phase space (Fig. 10) suggests that, despite the low dissipation rates, the flow is largely isotropic (Imberger and Ivey, 1991), but occasionally limited by the stratification (cf. Stacey et al., 1999). The small variation in $F r_{t}$ indicates that 


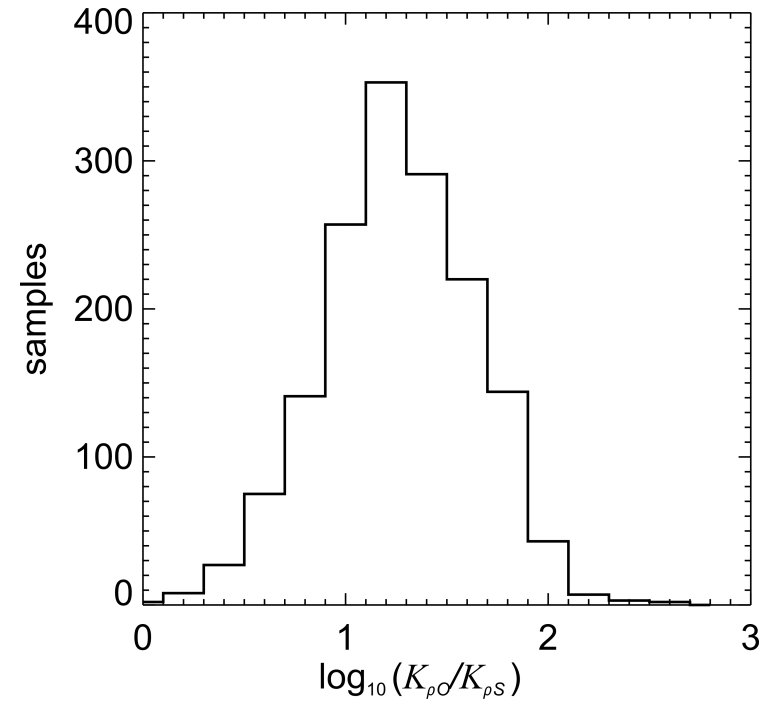

Fig. 8. Distribution of the ratio of the Osborn $K_{\rho O}$ and Shih et al. (2005) $K_{\rho S}$ vertical diffusivity estimates.

there is a relatively tight relationship between $L_{c}$ and $L_{O z}$ but with the eddies being close to their buoyancy-limited scale. These data are intermediate between the lake data of Imberger and Ivey (1991) and the highly energetic estuarine tidal flow of Stacey et al. (1999) and far from the highly stratified turbulence found in weakly tidal estuarine embayments (Stevens, 2003).

\subsection{Turbulence influence on frazil crystals and super- cooled water}

The smallest scales of overturning at, and just above, $L_{K}$ may have some influence in the present system on ice formation. This is because they aid aggregation and generate shear at the frazil crystal scale. In a survey of polar frazil crystal measurements, a few frazil crystal discs were found to be larger than $5-10 \mathrm{~mm}$ in radius, but most discs were smaller than $3 \mathrm{~mm}$ in radius (McGuiness et al., 2009). Smedsrud and Jenkins (2004) considered nascent frazil crystals to commence life at scales around one tenth of this. They then followed their growth in a suspended phase up to $0.8 \mathrm{~mm}$ in radius. McMurdo Sound waters appear to support conditions allowing frazil crystals to grow to far larger scales (Leonard et al., 2006) and the present authors have observed crystals exceeding $10 \mathrm{~cm}$ in radius. The derived estimates of $L_{K}$ are in the range $1-7 \mathrm{~mm}$ (Fig. 11), and by definition smaller than $L_{O z}$ and $L_{e}$. With spring tidal flows being around twice those during the observation period, the scaling $L_{K} \sim(1 / \varepsilon)^{1 / 4} \mathrm{im}$ plies a factor of $2^{(-3 / 4)}$ - so one might see a minimum $L_{K}$ around $0.6 \mathrm{~mm}$.

Comparison of crystal size and turbulence scales using the present data suggests the crystals start life at a scale smaller than the minimum eddy size, $L_{K}$, but grow to a scale be-

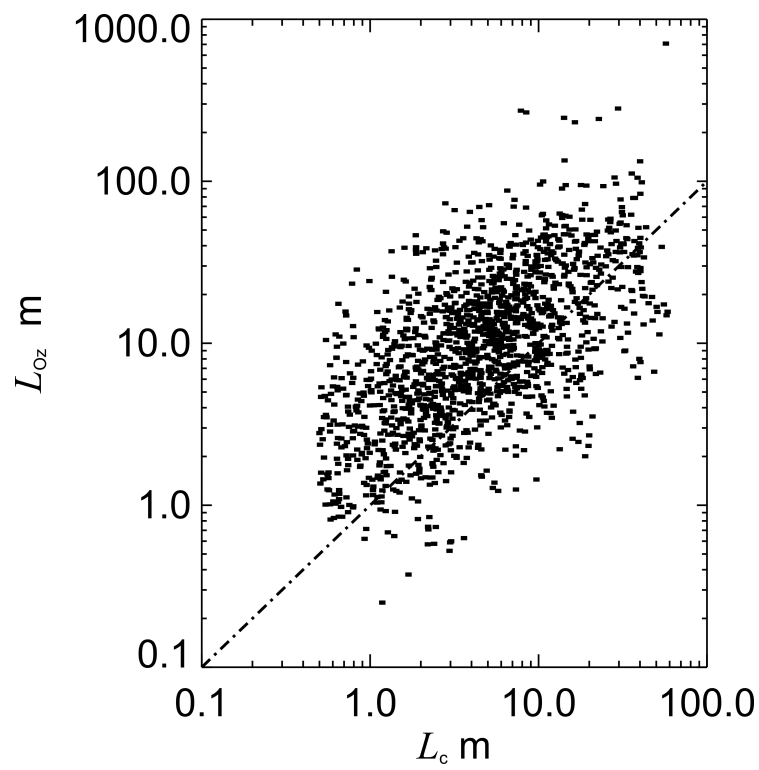

Fig. 9. Calculated Ozmidov lengthscale $L_{O Z}$ as a function of observed centred displacement scale $L_{c}$ for individual bins.

yond this. However, crystals of size smaller than $L_{K}$ still experience velocity shear. If we define $\phi=L_{f} / L_{K}$ where $L_{f}$ is the frazil crystal size, it is reasonable to expect the frazil crystals to experience shear of the order of $\phi V_{K} / L_{K}$ where $V_{K}$ is the Kolmogorov velocity scale $V_{K}=(\varepsilon v)^{1 / 4}$. With $\varepsilon$ in the range $2.0 \times 10^{-8}-5 \times 10^{-7} \mathrm{~m}^{2} \mathrm{~s}^{-3}$ then shear will be in the range $0.14-0.7 \mathrm{~s}^{-1}$. This comparability in scale between crystal size and $L_{K}$ also implies that there will be sufficient motion at the scale of the crystals to bring them together (and apart) thus influencing crystal-crystal interaction including breeding collision and possibly aggregation (e.g. Svensson and Omstedt, 1998).

Turbulence acts at scales greater than $L_{K}\left(R e_{t}>10\right)$ up until it reaches the bounding scale $L_{O z}\left(F r_{t}<1\right)$. If the large scales of turbulence dominate over smaller scales then it may promote rapid growth of even larger frazil crystals (Leonard et al., 2006; Dempsey et al., 2009) by sweeping supercooled water, originally at the base of the ice shelf-affected fluid layer, closer to the surface and so increasing the thermal deficit even more. However, this would require some form of covariance measurement in order to identify these upwards bursts of newly-supercooled water.

Questions relating to the influence of turbulence and stratification on sea ice production also exist at the scale of McMurdo Sound. The supercooled water exiting the McMurdo Ice Shelf Cavity, typically in the upper 30-50 m, will disperse through the Sound influencing frazil growth. It is useful to consider the role of vertical diffusion in this redistribution. The vertical flux of heat into the supercooled water layer is described by $F_{H}=\rho c_{p} K_{z} \partial \theta / \partial z$ (where specific heat capacity $c_{p}=4000 \mathrm{~J} \mathrm{~kg}^{-1}{ }^{\circ} \mathrm{C}^{-1}$ ) and is of the order of $0.3 \mathrm{~W} \mathrm{~m}^{-2}$ (from Fig. $7 \mathrm{c}, K_{\rho S}=5 \times 10^{-4} \mathrm{~m}^{2} \mathrm{~s}^{-1}$, 


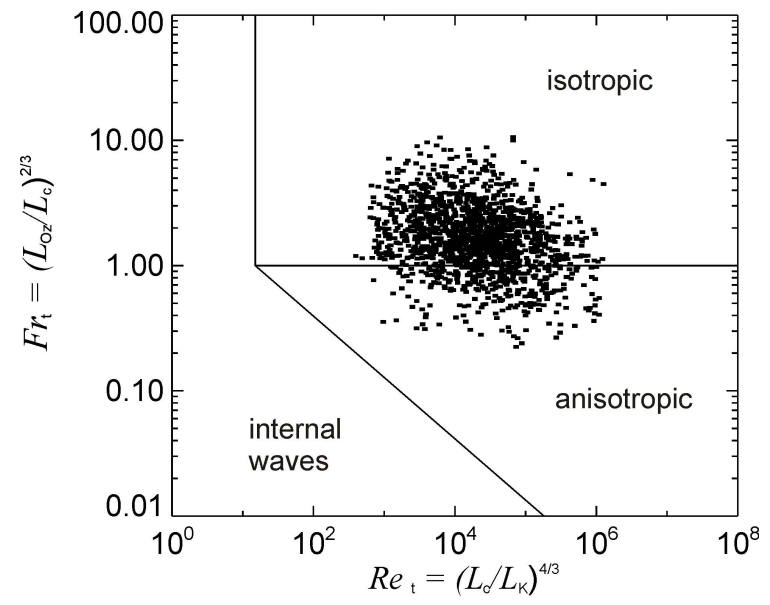

Fig. 10. Turbulent $F r t-R_{t}$ phase diagram with regimes associated with isotropy and internal waves (Imberger and Ivey, 1991).

$\left.d \theta / d z=0.005 / 30^{\circ} \mathrm{C} \mathrm{m}^{-1}\right)$. If the thermal energy deficit in the layer (thickness $h$, here taken as $50 \mathrm{~m}$ ), per unit area of the water column, is considered to be $E=\rho c_{p} h \Delta \theta$, then the time required for the supercooled layer to diffuse to a temperature above that of supercooling $\left(E / F_{H}\right)$ scales only with $K_{\rho S}$ and $h$ and is around 60 days. The local current residual is around $0.1 \mathrm{~m} \mathrm{~s}^{-1}$ (Robinson et al., 2009) is likely an upper bound for flows in the Sound-proper. Estimating a flow of around half this implies the supercooling should penetrate $\sim 250 \mathrm{~km}$ beyond the ice shelf front. This is over an order of magnitude larger than the tidal envelope in the region of around $10 \mathrm{~km}$ (Robinson et al., 2009). Although this persistence has not been directly observed in the Ross Sea, Hellmer's (2004) model analysis shows that the differences in sea ice with and without the ice shelf cavity extend for over $1000 \mathrm{~km}$ north from Ross Island.

\subsection{Under ice boundary-layer versus topographic effects}

The source of the observed mixing is obviously relevant to understanding how the mixing behaves under different conditions (e.g. season, tidal phase, location). There are three potential drivers of mixing. These are (i) the effect of ice shelf and sea ice on boundary-roughness and convective processes, (ii) the tide-topography interaction and (iii) baroclinic processes generating internal shear and ultimately mixing (e.g. McPhee, 1992; Fer and Widell, 2007). In the present location there are sharp changes in topography at the sea floor, along the shore and at the surface across the sea ice to ice shelf transition. All are likely to generate substantial internal motion and shear. With the large observed changes in density (Fig. 5c) being potentially related to flow-topography interaction it is important to examine the measurements to assess the relative importance of the under ice boundary layer. Local flow circulation drives bed and internal shear turbulence

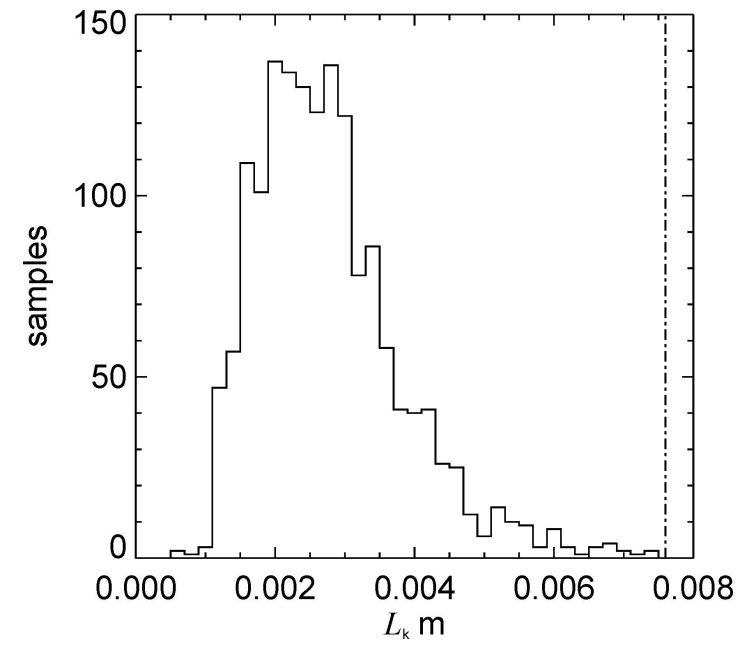

Fig. 11. Distribution of Kolmogorov lengthscale $L_{K}$, where the dashed line is an upper bound cut-off associated with the minimum resolvable energy dissipation rate.

as well as under-ice boundary turbulence. Consequently, it is difficult to separate the competing influences of sea ice boundary-friction from topographically-induced turbulence.

It is useful to compare the measured $\varepsilon$ nearest the ice to that expected from boundary-layer scaling. First, a friction velocity scale $u_{*}$ is derived using a drag coefficient approximation (Pease et al., 1983; McPhee, 2002) so that maximum $u_{*}$ is around $0.01 \mathrm{~m} \mathrm{~s}^{-1}$. We were unable to reliably sample at depths shallower than $6 \mathrm{~m}$ beneath the ice (i.e. depths $>8 \mathrm{~m}$ ). This is deeper than the planetary scale $0.03 u_{*} / f$ ( $f=$ Coriolis parameter $\sim 0.00014 \mathrm{~s}^{-1}$ at this latitude) associated with Coriolis' influence (McPhee, 2008) although it's not clear that this scale is unaffected by the influence of the local topography. Measured energy dissipation rates in the $8-13 \mathrm{~m}$ depth bin were around $2 \times 10^{-7} \mathrm{~m}^{2} \mathrm{~s}^{-3}$. The boundary-layer estimate $\varepsilon_{B L}$ using the scaling for the law of the wall whereby $\varepsilon_{B L}=u_{*}^{3} /(K z)$ (von Karman's constant $K=0.4$ ), so that using our uppermost measurements centred at $10.5 \mathrm{~m}$ depth, and for flows around $0.15 \mathrm{~m} \mathrm{~s}^{-1}$, we expect $\varepsilon=10^{-7} \mathrm{~m}^{2} \mathrm{~s}^{-3}$. Maximum observed dissipation levels were of this order although this is lower than the observations of Fer and Widell (2007) and McPhee (2002) where the dissipation rate near the under-side of the ice reached $10^{-6} \mathrm{~m}^{2} \mathrm{~s}^{-3}$.

Internal and benthic boundary layer processes can certainly generate dissipation rates of this order and higher in the case of benthic boundary layers. It is likely that in the middle of the water column reasonable and persistent stratification restricts mixing originating at the bed from influencing the supercooled water under the ice. The local maximum in dissipation rate just under the sea ice, the lower dissipation rate in the mid-upper column and the higher dissipation rates tracking the central pycnocline suggest that these processes act together and the influence on frazil ice and biology 
will depend very much where they are in a three-dimensional sense.

\subsection{Future work}

These first turbulence profiler observations from adjacent to the climatically important McMurdo Ice Shelf generate a number of themes for future examination. With improved survey work we hope to locate the major flow pathways in the region and repeat this dissipation rate sampling over a greater proportion of the spring-neap tidal cycle. Interestingly, as there seems to be something of a universality in the available literature with regard to observations all being most commonly from tides generating flows of around 0.1$0.25 \mathrm{~m} \mathrm{~s}^{-1}$. It would be interesting to consider these types of measurements and processes in both significantly slower and faster flow situations.

This, in conjunction with mooring work, will enable the development of a quasi-seasonal picture of the small-scale processes in the strait and associated region. Improved flux and exchange estimates will ultimately enhance our understanding of the way the McMurdo and Ross Ice Shelf Cavities interact with the wider Ross Sea and the implications this has for sea ice growth, ventilation of the sub-ice shelf cavity and the impact on ice shelf basal melt. But this large scale picture also requires work at the frazil crystal scale to understand how turbulence influences the actual growth, downward resuspension and aggregation processes of this ice, which forms a significant fraction of the sea ice cover in McMurdo Sound (Dempsey et al., 2009; Leonard et al., 2006; McGuiness et al., 2009).

Acknowledgements. Support was provided by Antarctica New Zealand and the New Zealand Foundation for Research Science and Technology Adaptation to Climate Contract C01X0202. Advice and assistance were provided by B. Staite, P. Langhorne, B. Grant, A. Mahoney, A. Gough and Rockland Scientific. The authors wish to thank Miles McPhee and William Shaw for their reviews of an earlier version of this paper.

Edited by: E. J. M. Delhez

\section{References}

Albrecht, N., Vennell, R., Williams, M., Stevens, C., Langhorne, P., Leonard, G., and Haskell, T.: Observation of sub-inertial internal tides in McMurdo Sound, Antarctica, Geophys. Res. Lett., 33, L24606, doi:10.1029/2006GL027377, 2006.

Arrigo, K. R., van Dijken, G., and Long, M.: Coastal Southern Ocean: A strong anthropogenic $\mathrm{CO}_{2}$ sink, Geophys. Res. Lett., 35, L21602, doi:10.1029/2008GL035624, 2008.

Dempsey, D., Langhorne, P. J., Robinson, N. J., Williams, M. W. M., Haskell, T. G., and Frew, R.: Observation and modeling of platelet ice fabric in McMurdo Sound, Antarctica, to appear, J. Geophys. Res., doi:10.1029/2008JC005264, in press, 2009.
Dillon, T. M.: Vertical Overturns: A Comparison of Thorpe and Ozmidov Length Scales, J. Geophys. Res., 87(C12), 9601-9613, 1982.

Fer, I. and Widell, K.: Early spring turbulent mixing in an icecovered Arctic fjord during transition to melting, Cont. Shelf Res., 27, 1980-1999, 2007.

Galbraith, P. S. and Kelley, D. E.: Identifying overturns in CTD profiles, J. Atmos. Ocean. Tech., 13, 688-702, 1996.

Goring, D. G. and Pyne, A.: Observations of sea-level variability in Ross Sea, Antarctica, N. Z. J. Mar. Freshwater Res., 37, 241249, 2003.

Hellmer, H. H.: Impact of Antarctic ice shelf melting on sea ice and deep ocean properties, Geophys. Res. Lett., 31, L10307, doi:10.1029/2004GL019506, 2004.

Holland, P. R., Feltham, D. R., and Jenkins, A.: Ice Shelf Water plume flow beneath Filchner-Ronne Ice Shelf, Antarctica, J. Geophys. Res., 112, C05044, doi:10.1029/2006JC003915, 2007.

Imberger, J. and Boashash, B.: Application of the Wigner-Ville distribution to temperature gradient microstructure: a new technique to study small-scale variations, J. Phys. Oceanogr., 16, 19972012, 1986.

Imberger, J. and Ivey, G. N.: On the nature of turbulence in a stratified fluid. Part II: Observations, J. Phys. Oceanogr., 21, 659-675, 1991.

Jacobs, S. S., Huppert, H. E., Holdsworth, G., and Drewry, D. J.: Thermohaline steps induced by melting of the Erebus Glacier Tongue, J. Geophys. Res., 86, 6547-6555, 1981.

Jacobs, S., Hellmer, H. H., and Jenkins, A.: Antarctic ice sheet melting in the Southeast Pacific. Geophys. Res. Lett., 23, 957960, 1996.

Keeler, R. N., Bondur, V. G., and Gibson, C. H.: Optical satellite imagery detection of internal wave effects from a submerged turbulent outfall in the stratified ocean, Geophys. Res. Lett., 32, L12610, doi:10.1029/2005GL022390, 2005.

Leonard, G. H., Purdie, C. R., Langhorne, P. J., Haskell, T. G., Williams, M. J. M., and Frew, R. D.: Observations of platelet ice growth and oceanographic conditions during the winter of 2003 in McMurdo Sound, Antarctica, J. Geophys. Res., 111, C04012, doi:10.1029/2005JC002952, 2006.

Lueck, R.: Horizontal and vertical turbulence profilers, in: Marine Turbulence: Theories, Observations and Models, edited by: Baumert, H. Z., Simpson, J. H., and Sundermann, J., Cambridge Univ. Press, 89-100, 2005.

Macoun, P. and Lueck, R. G.: Modelling the spatial response of the air-foil shear probe using different sized probes, J. Atmos. Ocean. Tech., 21, 284-297, 2004.

McGuiness, M. J., Williams, M. J. M., Langhorne, P. J., Purdie, C., and Crook, J.: Frazil deposition under growing sea ice, J. Geophys. Res., 114, C07014, doi:10.1029/2007JC004414, 2009.

McPhee, M. G.: Turbulent heat flux in the upper ocean under sea ice, J. Geophys. Res., 97, 5365-5379, 1992.

McPhee, M. G.: Turbulent stress at the ice/ocean interface and bottom surface hydraulic roughness during the SHEBA drift, J. Geophys. Res., 107, 8037, doi:10.1029/2000JC000633, 2002.

McPhee, M. G.: A spectral technique for estimating turbulent stress, scalar flux magnitude, and eddy viscosity in the ocean boundary layer under pack ice, J. Phys. Oceanogr., 34, 2180-2188, 2004.

McPhee, M. G.: Air-ice-ocean-interaction: Turbulent Ocean Boundary Layer Exchange Processes, Springer, 215 pp., 2008. 
McPhee, M. G. and Morison, J. H.: Turbulence and diffusion: Under-ice boundary layer, in: Encyclopedia of Ocean Sciences, Academic Press, London, 3071-3078, 2001.

McPhee, M. G. and Stanton, T. P.: Turbulence in the statically unstable oceanic boundary layer under Arctic leads, J. Geophys. Res., 101(C3), 6409-6428, 1996.

Mitchell, W. M. and Bye, J. A. T.: Observations in the boundary layer under the sea ice in McMurdo Sound, in: Oceanology of the Antarctic Continental Shelf, edited by: Jacobs, S. S., Antarctic Research Series, 63, 167-176, 1985.

Morison, J. H., Andersen, R. H., Larsen, N., D’Asaro, E. A., and Boyd, T.: The correction for thermal inertia effects in Sea-Bird CTD data, J. Atmos. Ocean. Tech., 11, 1151-1164, 1994.

Muench, R., Padman, L., Gordon, A., and Orsi, A.: A dense water outflow from the Ross Sea, Antarctica: Mixing and the contribution of tides, J. Mar. Sys., 77, 369-387, doi:10.1016/j.jmarsys.2008.11.003, 2009.

Osborn, T.: Estimates of the local rate of vertical diffusion from dissipation measurements, J. Phys. Oceanogr., 10, 83-89, 1980.

Payne, A. J., Holland, P. R., Shepherd, A. P., Rutt, I. C., Jenkins, A., and Joughin, I.: Numerical modeling of ocean-ice interactions under Pine Island Bay's ice shelf, J. Geophys. Res., 112, C10019, doi:10.1029/2006JC003733, 2007.

Pease, C. H., Salo, S. A., and Overland, J. E.: Drag measurements for first-year sea ice over a shallow sea, J. Geophys. Res., 88, 2853-2862, 1983.

Prandke, H.: Microstructure sensors, in: Marine Turbulence: Theories, Observations and Models, edited by: Baumert, H. Z., Simpson, J. H., and Sundermann, J., Cambridge Univ. Press, 101-109, 2005.

Rainville, L., Winsor, P.: Mixing across the Arctic Ocean: Microstructure observations during the Beringia 2005 Expedition, Geophys. Res. Lett., 35, L08606, doi:10.1029/2008GL033532, 2008.

Robertson, R. A., Padman, L., and Levine, M. D.: Finestructure, microstructure, and vertical mixing processes in the western Weddell Sea, J. Geophys Res., 100, 18517-18535, 1995.

Robinson, N. J., Williams, M. J. W., Barrett, P. J., and Pyne, A. R.: Observations of flow and ice-ocean interactions beneath the McMurdo Ice Shelf, Antarctica, J. Geophys. Res., accepted, 2009.

Roget, E., Lozovatsky, I., Sanchez, X., and Figueroa, M.: Microstructure measurements in natural waters: Methodology and applications, Prog. Oceanogr., 70, 126-148, 2006.

Shaw, W. J., Stanton, T. P., McPhee, M. G., Morison, J. H., and Martinson, D. G.: Role of the upper ocean in the energy budget of Arctic sea ice during SHEBA, J. Geophys. Res., 114, C06012, doi:10.1029/2008JC004991, 2009.
Shih, L. H., Koseff, J. R., Ivey, G. N., and Ferziger, J. H.: Parameterization of turbulent fluxes and scales using homogeneous sheared stably stratified turbulence simulations, J. Fluid Mech., 525, 193-214, 2005.

Smedsrud, L. H. and Jenkins, A.: Frazil ice formation in an ice shelf water plume, J. Geophys. Res., 109, C03025, doi:10.1029/2003JC001851, 2004.

Stacey, M. T., Monismith, S. G., and Burau, J. R.: Observations of turbulence in a partially stratified estuary, J. Phys. Oceanogr., 29, 1950-1970, 1999.

Stacey, M. T., Burau, J. R., and Monismith, S. G.: Creation of residual flows in a partially stratified estuary. J. Geophys. Res., 106, 17013-17037, 2001.

Stevens, C.: Turbulence in an Estuarine Embayment: Observations from Beatrix Bay, New Zealand, J. Geophys. Res., 108(C2), 3030, doi:10.1029/2001JC001221, 2003.

Stevens, C. L. and Smith, M. J.: Temperature microstructure beneath surface gravity waves, J. Atmos. Ocean. Tech. 21, 17471757, 2004.

Stevens, C. L., Williams, M. J. M, Robinson, N. J., Albrecht, N., and Haskell, T. G.: Observations of the Stratified Turbulent Boundary-layer and Platelet Ice Beneath McMurdo Sound Sea Ice, Proc. Sixth International Symposium on Stratified Flows, edited by: Ivey, G. N., Perth, Australia, 2006.

St. Laurent, L.: Turbulent dissipation on the margins of the South China Sea, Geophys. Res. Lett., 35, L23615, doi:10.1029/2008GL035520, 2008.

Stroeve, J., Holland, M. M., Meier, W., Scambos, T., and Serreze, M.: Arctic sea ice decline: Faster than forecast, Geophys. Res. Lett., 34, L09501, doi:10.1029/2007GL029703, 2007.

Svensson, U. and Omstedt, A.: Simulation of supercooling and size distribution in frazil ice dynamics, Cold Reg. Sci. Technol., 22, 221-233, 1994.

Tennekes, H. and Lumley, J. L.: A First Course in Turbulence, MIT Press, 300 pp., 1972.

Wesson, J. C. and Gregg, M. C.: Mixing at Camarinal Sill in the Strait of Gibraltar, J. Geophys. Res., 99, 9847-9878, 1994.

Williams, M. J. M., Grosfeld, K., Warner, R. C., Gerdes, R., and Determann, J.: Ocean circulation and ice-ocean interaction beneath the Amery Ice Shelf, Antarctica, J. Geophys. Res., 106, 22383-22399, 2001.

Zaron, E. D. and Egbert, G. D.: Estimating open-ocean barotropic tidal dissipation: The Hawaiian Ridge, J. Phys. Oceanogr., 36, 1019-1035, 2006. 